Int. J. Electrochem. Sci., 11 (2016) 10407 - 10416

\title{
Electrochemical Detection of Liquiritin in Liquorice Based on Carbon Materials
}

\author{
Mei Wang ${ }^{1, *}$, Yingjuan $Q u^{2}$, Jing Sun ${ }^{1}$, Jinglin $\mathrm{Li}^{1}$, Suiling Zhang ${ }^{1}$ and Yajun Shi ${ }^{1}$ \\ ${ }^{1}$ College of Pharmacy, Shaanxi University of Chinese Medicine, Xianyang, Shaanxi, 712046, P.R. \\ China \\ ${ }^{2}$ School of Chemical Engineering, Xi' an University, Xi' an, Shaanxi, 710065, P.R. China \\ *E-mail: meiwang_cpsu@yahoo.com
}

doi: $10.20964 / 2016.12 .24$

Received: 12 August 2016 / Accepted: 4 October 2016 / Published: 10 November 2016

To quantify liquiritin, an electrochemical sensor was synthesized with a glassy carbon electrode (GCE), which was modified by the carboxylic acid-based graphene (C-GO) and acidified MWCNT. Compared with the original GCE, the GCE after modification with MWCNT or C-GO exhibited a well-defined oxidation and reduction of liguiritin. Moreover, the current response was enhanced significantly by this process, where the current response of the oxidation peak of liquiritin showed a linear relationship with the concentration of liquiritin in the range of 0.05 to $100 \mu \mathrm{M}$ when the limit of detection was $0.03 \mu \mathrm{M}$. The modified voltammetric performance of the electrochemical sensor demonstrated that it could be practically applied in the determination of liquiritin for the real licorice specimens.

Keywords: Electrochemistry, Sensor, Liquiritin, Liquorice, Carbon nanotube; Graphene

\section{$\underline{\text { FULL TEXT }}$}

(C) 2016 The Authors. Published by ESG (www.electrochemsci.org). This article is an open access article distributed under the terms and conditions of the Creative Commons Attribution license (http://creativecommons.org/licenses/by/4.0/). 